\title{
Therapeutic Potentials of CD151 shRNA in Targeting Metastasis of Triple Negative Breast Cancer Cell Line MDA-MB-231
}

\author{
Gayatri Devi V, Anil Badana, Seema Kumari, Nagaseshu P and Rama Rao Malla*
}

Department of Biochemistry, Cancer Biology Lab, GIS, GITAM University, Vizag, India

\begin{abstract}
Objective: $\mathrm{CD} 151$ is a master regulator of cell adhesion signalling and acts as a promoter in tumour progression. Induction of RNAi through shRNA expression holds great prospective in biomedical research. Bioinformatics approach used to predict potential shRNAs that knockdown CD151. The aim of present study is to investigate the role of CD151 in metastasis of triple negative breast cancer cells using shRNA.
\end{abstract}

Methods: Triple negative breast cancer line, MDA-MB-231 obtained from NCCS Pune, India and expression of CD151 determined using western blot and RT-PCR analysis. Small hairpin RNA (shRNA) was constructed using pSilencer 2.1-U6 puro vector to knockdown CD151 expression. The role of CD151 in proliferation, apoptosis, migration, invasion and cell adhesion was evaluated by silencing CD151 gene using CD151shRNA.

Results: RNA interference technology (RNAi) used to silence CD151 gene expression in MDA-MB-231 cells. Delivery of specific shRNA targeting human endogenous CD151 showed significant growth inhibition of MDAMB-231 cells. The gene expression study by RT-PCR analysis showed that expression of CD151 at mRNA level reduced six fold with CD151 gene knockdown. CD151 gene silencing for 48h using shRNA decreased proliferation by $62.7 \%$. CD 151 knockdown also lead to the significant inhibition of metastasis and induced apoptosis.

Conclusion: CD151 over expression is essential for tumour progression and our study shows that shRNA mediated gene silencing of CD151 decreases the metastasis, thus emphasizing CD151 as a prognostic marker and help in developing new therapeutics for treatment of triple negative breast cancer.

\section{Keywords: CD151; shRNA; MDA-MB-231; Metastasis; Apoptosis}

\section{Introduction}

Cancer is well recognized as a global health problem for decades. It defined as collection of diseases characterized by abnormal cell growth, violating the cell division rules and spreads to the surrounding tissues. While specific signals dictate the cell division in healthy cells, cancer cells develop a degree of autonomy resulting in uncontrolled proliferation leading to tumour development. Most of the cancerrelated deaths (90\%) are due to spreading of tumour cells to other body parts, a process called as metastasis.

Breast cancer is one of the most common cancers diagnosed in women in India and worldwide. It is the second most frequent cause of death due to cancer in women. In the year 2015, 1,55,000 new breast cancer cases were expected and of, 76,000 women were expected to die. WHO ironically stated that most of the breast cancer cases in India were diagnosing at stage III or IV that drastically affects the survival rate and treatment options. Today there are choices of treatment options that fight with complex mix of cells in breast cancer, including surgery, radiation, hormonal (anti-estrogen) therapy and chemotherapy [1]. Majority of breast cancer deaths are because of ineffective treatment of metastatic disease. Therefore, metastatic breast cancer patients need to treat with targeted therapies directed at specific molecular alterations.

The tetraspanin transmembrane proteins have emerged as key gamer in malignancy and have variety of specific molecular interactions through formation of tetraspanin-enriched microdomains [2]. Tetraspanins have emerged as diagnostic and prognostic markers and gained increased attention due to their functional versatility [3]. CD151 is one among them, reported as an adaptor molecule [4]. It is expressed on normal cells but over expressed on cancer cells. It functions at multiple cancer stages [5], particularly implicated in tumour metastasis [6]. It also functions as an important regulator of communication between tumour cells and endothelial cells [7], carcinoma-stroma interactions cell-cell and cell-ECM interactions [8]. Earlier, the role of CD151 demonstrated in variety of signalling mechanisms [9-14]. It promotes tumour angiogenesis [15], growth and survival [16] and metastasis [17-20]. High expression of CD151 confers poor prognosis in breast [21]. Our recent review highlighted the role of CD151 in tumour metastasis and its importance in cancer therapy [22]. CD151 may represent new therapeutic target as it is simultaneously affecting the proteolytic activity of different enzymes, signalling and different cellular mechanisms.

Targeting of CD151 using monoclonal antibodies displayed antimetastatic activity in vivo [5]. Blocking of CD151 using mAbs inhibited the tumour growth [5], migration [23] and metastasis [18] in several cancers. Several limitations highlighted in clinical and animal studies hampered the use of mAbs in cancer therapy. In addition, the large size of mAbs decreases the penetration and retention of the therapeutic antibody in the malignant tissues and thus reducing the efficiency of the treatment [24].

RNA interference (RNAi) is relatively innovative discovery for inhibiting gene expression and target mediated treatment of cancer.

*Corresponding author: Malla RR, Department of Biochemistry, Cancer Biology Lab, Institute of Science, GITAM University, Visakhapatnam, Andhra Pradesh, 530045 India, Tel: +91-7386168249; E-mail: rrmalla@gitam.edu,dr.rrmalla@gmail.com

Received February 24, 2016; Accepted April 26, 2016; Published April 28, 2016

Citation: Gayatri Devi V, Badana A, Kumari S, Nagaseshu P, Malla RR (2016) Therapeutic Potentials of CD151 shRNA in Targeting Metastasis of Triple Negative Breast Cancer Cell Line MDA-MB-231. J Cancer Sci Ther 8: 104-112. doi:10.4172/1948-5956.1000400

Copyright: ( 2016 Gayatri Devi V, et al. This is an open-access article distributed under the terms of the Creative Commons Attribution License, which permits unrestricted use, distribution, and reproduction in any medium, provided the original author and source are credited. 
Earlier methodologies have incorporated antisense technology and catalytic ribozymes. However, the efficacy of these approaches is mixed, particularly in inhibiting established tumours. The stableness/specificity of the oligonucleotides and issues in target collection choice impede the extensive use of those techniques [25]. Analysis of the kinetics of siRNA-mediated gene silencing reveals that the gene inhibition by unmodified siRNAs can last for a week in rapidly dividing cells and up to one month in cells with minimal division. shRNA is highly effective tool used to silence expression of specific genes. RNA interference (RNAi) mediated by small interfering RNAs (siRNAs) or short hairpin RNAs (shRNAs) has emerged as a powerful genetic tool to investigate the functional studies. There are several methods to induce RNAi for gene knockdown [26] but commonly used methods are chemically synthesized siRNAs and shRNA expression vectors. Compared to chemically synthesized siRNAs, vector-based shRNA induce transient expression when introduced in to the vector [27].

Targeting of CD151 using shRNA can overcome the limitations of using mAbs, as shRNA are highly specific and smaller. Moreover, synthesis of CD151 shRNA is inexpensive as it is only a 20-25 nt long RNA fragment. shRNA is chemically modified and introduced in to cells by using expression vectors. This type of expression plasmids transiently expressed in the cell and show stable gene silencing.

\section{Materials and Methods}

\section{Prediction of cellular, molecular and biological functions of CD151}

CD151 protein network in Homo sapiens constructed using STRING online search tool, subjected to K-mean clustering and its role in biological process, molecular functions and cellular components analyzed by enrichment with genome, kinome and druggable backgrounds.

\section{Prediction of CD151 gene expression pattern using GENT database}

CD151 expression pattern in human normal and tumour tissues, subtypes and cancer cell line retrieved from GENT database created by the Afymetrix U133Plus2 and U133A platforms (http:// medicalgenome.kribb.re.kr/GENT/ or genome.kobic.re.kr/GENT/). Expression of CD151 detected by cancer outlier profile analysis (COPA) and visualized by box-plot [28].

\section{Design of CD151 shRNA template oligonucleotides}

Gene silencing using shRNA is a rapidly evolving tool in molecular biology. By scanning CD151 mRNA (cds) for AA dinucleotide sequences start from AUG and potential target sequences from +91 , $+210,+393$ and +824 were identified [29]. Finally two sets of potential target sequences were obtained by comparing above target sequences to human genome database and by eliminating target sequences that have homology of 16-17 contiguous base pairs to other coding sequences using BLAST search (5'-GATCCGAGTTCAACGAGAAGAAGACATCAAGAGTGTCTTCTTCTCGTTGAACTCTTTTTGGAAA-3' and 3'-GCTCAAGTTG CTCTTCTTCTGTAGTTC TCACAGAAGAAGAGCAAC TTGAGAAAAACC TTT TCGA-5' for construct A (pCD-A); 5'- GATCCGGAGATCATCGCTGGTATCCTTCAAGAGAGG AT AC C AGCGATGATCTCCTTTTTGGAAA-3' and 3'GCCTCTAGTAGCGACCATAGGA AGTTC TCTC CTAT GGTCGCTACTAGAGGAAAAACCTTTTCGA-5' for construct B (pCD-B). Hairpin siRNA template oligonucleotides were designed from target sequences using web-based insert design tool (www. ambion.com/techlib/misc/ pSilencer_converter.html).

\section{Construction of CD151shRNA expressing vector}

Desalted complementary oligonucleotides with loop sequence of 5'-UUCAAGAGA-3' at centre and 5 nucleotide poly (T) tract as a termination signal for RNA pol III at 3'-end and BamH1 or HindIII restriction site at 5'-end was commercially obtained. Two selfcomplementary oligonucleotides annealed by heating at $90^{\circ} \mathrm{C}$ for $3 \mathrm{~min}$ and cooled to room temperature in 6x SSC which leads to formation of dsDNA molecules with respective sticky restriction site ends. These dsDNA molecules were ligated to linearized pSilencer 2.1 -u6 puro vector between Bam H1 and HindIII restriction sites. This finally resulted in a shRNA expression plasmid for CD151 (pCD). Non-targeting negative control shRNA (pSV) also constructed with scrambled nucleotide sequence of the CD151 shRNA.

\section{Identification of clones with shRNA inserts}

Standard protocol used for transformation of E. coli cells [30]. CD151 shRNA expression plasmid $(5 \mu \mathrm{l})$ added to $100 \mu \mathrm{l}$ of DH5a competent cells. The content was kept in water bath at $42^{\circ} \mathrm{C}$ for $90 \mathrm{sec}$ for heat shock treatment and immediately chilled for $5 \mathrm{~min}$. $1 \mathrm{ml}$ of LB broth was added and incubated at $37^{\circ} \mathrm{C}$ for $45 \mathrm{~min}$. Cell suspension $(100 \mu \mathrm{l})$ from each transformed culture was added to LB agar plate containing ampicillin $(100 \mu \mathrm{g} / \mathrm{ml})$ and incubated overnight at $37^{\circ} \mathrm{C}$. Isolated colonies were selected and inoculated in to $4 \mathrm{ml}$ of $\mathrm{LB}$ broth containing ampicillin $(100 \mu \mathrm{g} / \mathrm{ml})$ and incubated at $37^{\circ} \mathrm{C}$ for $8 \mathrm{~h}$ with vigorous shaking $(200 \mathrm{rpm}) .100 \mu \mathrm{l}$ of this starter culture was added to $100 \mathrm{ml}$ of LB medium containing ampicillin $(100 \mu \mathrm{g} / \mathrm{ml})$ and grown overnight at $37^{\circ} \mathrm{C}$ with vigorous shaking $(200 \mathrm{rpm})$. Plasmid was isolated and purified using QIAGEN Plasmid Maxi kits as per the manufacture's protocol. The isolated plasmid digested with BamH1 and Hind III to confirm presence of the shRNA template insert.

\section{Cell culture and transfection}

The MDA-MB-231 is triple negative breast cancer cell line, established from human pleural effusions, obtained from NCCS, Pune, India. Cells were grown in Leibovitz's L-15 medium supplemented with $10 \%$ fetal bovine serum in a free gas exchange with atmospheric air at $37^{\circ} \mathrm{C}$. MCF-12A, a non-tumourigenic breast epithelial cell line, was grown in a mixture of Dulbecco's modified Eagle's medium and Ham's F12 medium (1:1) containing $20 \mathrm{ng} / \mathrm{ml}$ human epidermal growth factor, $100 \mathrm{ng} / \mathrm{ml}$ cholera toxin, $0.01 \mathrm{mg} / \mathrm{ml}$ bovine insulin and $500 \mathrm{ng} /$ $\mathrm{ml}$ hydrocortisone and $5 \%$ horse serum under humidified atmosphere of $5 \% \mathrm{CO}_{2}$. Monolayer of MDA-MB-231 cells grown overnight $(\sim 80 \%$ confluence) were transfected with 1-2 $\mu$ g of pSV or pCD shRNA plasmid using Lipofectamine 3000 Reagent (Life Technologies, USA) as per manufacturer's instructions. After $8 \mathrm{~h}$ of transfection, the medium replaced with serum containing medium and incubated for 24 or $48 \mathrm{~h}$. Expression of CD151 determined by RT-PCR analysis and compared with control (pSV).

\section{Reverse transcription-PCR analysis of down regulation of CD151 mRNA with pCD151}

Total RNA was extracted using TRIZOL reagent as per manufacturer's instructions (Invitrogen.USA). DNase-treated RNA used as a template for reverse transcription reaction followed by PCR analysis (Qiagen, USA) using sequence specific primers for CD151 and GAPDH (Table 1). The PCR conditions were as follows: 3 min at $93^{\circ} \mathrm{C}$ for initial denaturation of template DNA, 35 cycles at $93^{\circ} \mathrm{C}$ for $15 \mathrm{sec}-$ denaturation, annealing at $62^{\circ} \mathrm{C}$ for $30 \mathrm{sec}$ and extension at $68^{\circ} \mathrm{C}$ for 1 $\mathrm{min} / \mathrm{Kb}$, with a final extension step of $7 \mathrm{~min}$ at $72^{\circ} \mathrm{C}$. The PCR products were analysed on in $1 \%$ agarose gel electrophoresis. Intensity of bands was measured using Image J software (NIH, USA). 


\begin{tabular}{|c|c|c|}
\hline \multicolumn{2}{|c|}{} & \\
\hline Gene & Forward primer & Reverse primer \\
\hline CD151 & 5'-CAAGGCCGAGATCGTTCC-3' & 5'-ACAGCAGTGTACAAAACCAGG-3' $^{\prime}$ \\
\hline GAPDH & 5'-CAAGGTCATCCATGACAACTTTG-3' & 5'-GTCCACCACCCTGTTGCTGTAG-3' \\
\hline
\end{tabular}

Table 1: Genes analysed by RT-PCR.

\section{MTT assay}

MTT assay used to evaluate the effect of CD151 gene silencing using pCD on proliferation of MDA-MB-231 and MCF-12A cells. Monolayer cells in 96-well plate $\left(5 \times 10^{3} /\right.$ well $)$ were transfected with $1 \mu \mathrm{g}$ of $\mathrm{pCD}$-B for 24 and $48 \mathrm{~h}$ using Lipofectamine. pSV transfected cells maintained under similar conditions to serve as the control. After transfection, MTT reagent ( $5 \mathrm{mg} / \mathrm{ml}$ of PBS) added to each well, incubated for $2 \mathrm{~h}$ for color development and DMSO was added to solubilize formazan crystals. Absorbance at $595 \mathrm{~nm}$ was measured using ELISA plate reader. The percent reduction of cell viability expressed by comparing with to pSV treated cells, which set as $100 \%$.

\section{Brdu incorporation assay}

BrdU incorporation assay used to measure effect of $\mathrm{pCD}$ on cell proliferation. Cells $\left(10 \times 10^{3} /\right.$ well $)$ were seeded in triplicate into 96 well plates and allowed to grow overnight before transfection with pSV or pCD for $48 \mathrm{~h}$. After incubation, cells were labeled with diluted BrdU (1:2000 in tissue culture medium) for $12 \mathrm{~h}$. Cells were fixed with fixative solution and incubated for $30 \mathrm{~min}$ at room temperature. After incubation, anti-BrdU antibody (1:100) added and incubated for 1 $\mathrm{h}$ at room temperature. After washing, conjugate antibody (1:2000) added and incubated for $30 \mathrm{~min}$ at room temperature. After washing, tetra-methylbenzidine substrate added and incubated in dark for 15 min. Then stop solution was added and absorbance was read at dual wavelength of 450 and $540 \mathrm{~nm}$ within $30 \mathrm{~min}$.

\section{Adhesion assay}

The effect of CD151 gene silencing using $\mathrm{pCD}$ on the adhesive properties of MDA-MB- 231 breast cancer cells was determined by Adhesion assay. 96-well plate was coated with various ECM components. Briefly, $100 \mu \mathrm{L}$ of fibronectin $(10 \mu \mathrm{g} / \mathrm{mL}$; Sigma-Aldrich $)$, vitronectin ( $5 \mu \mathrm{g} / \mathrm{mL}$; Invitrogen), laminin $(5 \mu \mathrm{g} / \mathrm{mL}$; Sigma-Aldrich) and collagen I ( $50 \mu \mathrm{g} / \mathrm{mL}$; Invitrogen) were added separately to each well and incubated at $37^{\circ} \mathrm{C}$ for $1 \mathrm{hr}$. The wells were blocked with $0.2 \%$ BSA for $2 \mathrm{~h}$ at room temperature. After washing with PBS, $100 \mu \mathrm{l}$ of suspension of cells transfected earlier with pSV and pCD151 for $48 \mathrm{~h}$ were loaded in to each well. The cells were allowed to adhere for $2 \mathrm{~h}$, then washed carefully, fixed with methanol and stained with Hema-3 stain. The cells were extracted into $10 \%$ methanol and 5\% acetic acid and absorbance was read at $650 \mathrm{~nm}$ using ELISA plate reader.

\section{Wound scratch assay}

To study cell migration, cells were seeded in a 6-well plate at density of $\left(2 \times 10^{6} /\right.$ well $)$ and transfected with pSV or pCD for $48 \mathrm{~h}$. Then, a straight scratch was made in individual wells with a $200 \mu \mathrm{L}$ pipette tip. This point was considered the " $0 \mathrm{~h}$," and the width of the wound was photographed under the microscope. Then wound healing was checked under microscope and photographed at $0 \mathrm{~h}, 24 \mathrm{~h}$ and $48 \mathrm{~h}$. Wound healing was measured by calculating the reduction in the width of the wound after incubation and compared to $0 \mathrm{~h}$ which is set as $100 \%$.

\section{Matrigel invasion assay}

Matrigel assay used to determine the effect of $\mathrm{pCD}$ on invasive ability of MDA-MB-231 cells. Breast cancer cells $\left(2 \times 10^{5} /\right.$ well $)$ were transfected with pSV and pCD for $48 \mathrm{~h}$. After the incubation period, cells were trypsinized and suspended in $100 \mu \mathrm{L}$ of serum-free medium. The cells were seeded into the upper chamber of Boyden chamber filters ( $8 \mu \mathrm{m}$ pore) coated with Matrigel $(50 \mu \mathrm{g} /$ filter $)$ and $600 \mu \mathrm{L}$ complete medium was added to the lower chamber. The cell were allowed to migrate for $12 \mathrm{~h}$. The cells invaded through the Matrigel coated inserts were fixed with formaldehyde (3.7\% in PBS), stained with $0.4 \%$ crystal violet, and destained twice with PBS. Non invaded cells were scrapped with cotton swab and counted in random microscopic fields.

\section{Tunnel assay}

One of the most widely adopted method of choice for detecting DNA damage in situ is TdT-mediated dUTP-biotin nick end labelling (TUNEL) assay. Cells were transfected with pSV and pCD for 48 and $72 \mathrm{~h}$. After transfection, cells fixed with $4 \%$ Para-formaldehyde and incubated with a reaction mixture containing biotin-dUTP and terminal deoxynucleotidyl transferase for $1 \mathrm{~h}$. Then cells stained with DAPI and fluorescein-labelled cells visualized with fluorescent microscopy and expressed as percent compared to DAPI stained cells.

\section{Statistical analysis}

Statistical analysis and graphical exploration of the data were done using Microsoft Excel. All the experiments were carried out three times. Values are shown as means $\pm \mathrm{SD}$ of at least three independent experiments. Significance set as $\mathrm{p}<0.001$.

\section{Results}

\section{Functional analysis of CD151}

Understating the role of CD151 is required to target survival, angiogenesis and metastasis of cancers. search tool for the retrieval of interacting genes/proteins (STRING) is a biological database developed by a consortium of academic institutions. To predict gene ontology, CD151 interaction partners were clustered using k-means and enrichment of the associated functional annotations measured to generate putative functions. These results show that CD151 is a key cellular component of membrane, focal adhesion, extracellular matrix, basement membrane and cell junctions. CD151 was predicted to be actively involved in biological processes like extracellular matrix organization, hemidesmosome assembly, cellular component organization and cell junction assembly. During which it may perform several molecular functions such as receptor binding, ligase activity, ubiquitin like protein transferase activity and adhesion molecular binding. Further, human disease associations (http://tissues.jensenlab. org) and tissue annotations (http://diseases.jensenlab.org) of CD151 were done using enrichment detection. The results revealed that CD151 associate with cancer having Z-score of 3.6 and confidence of 2.0. The results from tissue annotations indicate that $\mathrm{CD} 151$ protein localized mostly in breast glandular cells and low in myoepithelial cells but not detected in adipose tissue.

\section{CD151 gene expression pattern in human normal and tumour tissues, subtypes and cancer cell lines}

The use of focused treatments directed at specific molecular change benefits breast cancer sufferers. Human tissue gene expression facts sets 
produced the usage of Affymetrix U133A and U133lPus2 platforms constructed from public sources and huge-scale gene expression database of greater than 40,000 samples used to explore for CD151 over expression. The result shows that CD151 was over expressed in subset of breast, kidney, lung and brain tumour tissues (Figures 1a and 1b) and in subset of cell lines from those four tissues (Figures $1 \mathrm{c}$ and $1 \mathrm{~d}$ ).

\section{Endogenous expression of CD151 in MDA-MB-231 and MCF-12A}

Triple negative breast cancer (TNBC) represents about $10-15 \%$ of all breast cancers and sufferers with TNBC have a poor prognosis compared to the other subtypes [31]. Given the lack of proven molecular targets and the poor final results in sufferers with TNBC, there's a transparent need for identification of molecular target. Most cancer cell lines have proved beneficial in laboratory and preclinical investigations [32]. Review of the literature found twenty- seven human breast cancer cell lines, which classified as TNBC cell lines. The MDAMB-231 breast cancer cell line obtained from a patient in 1973 at M. D. Anderson Cancer Centre. MDA-MB-231 breast cancer cells appear in spindle shape with epithelial-like morphology and invasive phenotype [33].

Preliminary study using GENT database predicted over expression of CD151 in MDA-MB-231 breast cancer cell line (Figures 2a and 2b). Hence, MDA-MB-231 cells used to evaluate the effect of CD151 shRNA on metastasis. We first attempted to compare the expression level of CD151 in human triple negative breast cancer cell line, MDA-MB-231 with human normal breast epithelial cell line, MCF-12A using western blot and RT PCR analysis. As shown in Figure 2c, CD151 protein level was significantly higher in MDA-MB-231cells as compared with the MCF-12A, which expressed undetectable levels of this protein. Similar trend seen in CD151 expression at mRNA level as assessed by RT-PCR analysis (Figure $2 \mathrm{~d}$ ).

\section{Knockdown of CD151 gene expression in MDA-MB-231 triple negative breast cancer cells using RNAi}

To study the biological role of CD151 in triple negative breast cancer metastasis, we used small hairpin RNAs to knockdown endogenous CD151 gene expression in MDA-MB-231 cells, which showed robust expression of CD151 as well as high metastatic potential. First, we constructed two sets of pSilencer vectors containing small hairpin capable of generating 21-nucleotide duplex RNAi oligonucleotides corresponding to CD151 (Figure 3a). Presence of shRNA insert confirmed by restriction digestion followed by electrophoresis (Data not shown).Then vectors expressing shRNA-for CD151 were transfected into MDA-MB-231 cells for 24 and $48 \mathrm{~h}$. Analysis of transfected cells via semi-quantitative reverse transcription-PCR demonstrated significant reduction in CD151 expression at mRNA level with pCD-B (Figure 3b). Densitometric analysis using Image J software indicates the reduction of CD151 expression at mRNA by $63.8 \%$ at $24 \mathrm{~h}$ and $85 \%$ at $48 \mathrm{~h}$ relative to pSV-transfected cells, which set as $100 \%$ (Figure 3c). However, effect of pCD-A plasmid on expression of CD151 was negligible (Data not shown). Conversely, no effect of $\mathrm{pCD}$ was observed on the expression of GAPDH, which used as an internal control for specificity and loading at mRNA level. As pSV transfection did not effected mRNA expression indicating that RNAi-directed CD151 knockdown is specific.

\section{Knockdown of CD151 expression by RNAi induces toxicity in triple negative breast cancer}

As preliminary study, cytotoxic effect of CD151 shRNA expression plasmids on non-tumourigenic cell line, MCF-12A was tested. After 48 $\mathrm{h}$ of transfection with $1 \mu \mathrm{g}$ of shRNA specific to CD151, viability of MCF-12A cells was $\sim 98 \%$ (Figure $4 \mathrm{a}$ ). To test the potential cytotoxic effects of RNAi-mediated CD151 silencing on viability of MDA-MB-231 cells, MTT assay performed after transfection with $1 \mu \mathrm{g}$ of pCD for 24 and $48 \mathrm{~h}$. The results showed that there is a significant reduction of viability with shRNA targeting CD151. Percent of viable cells was 46.2 a)

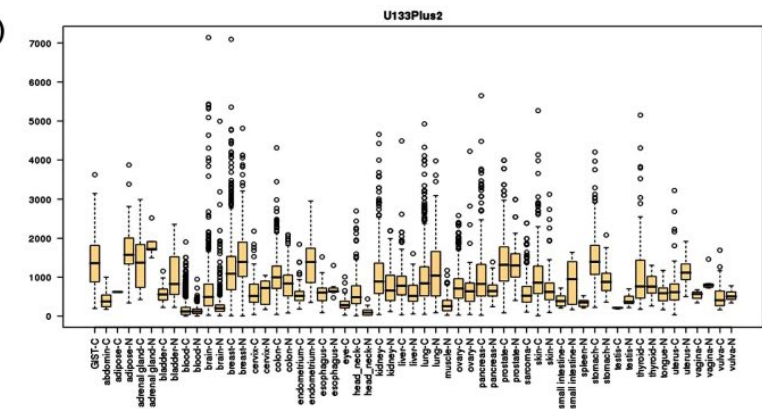

c)

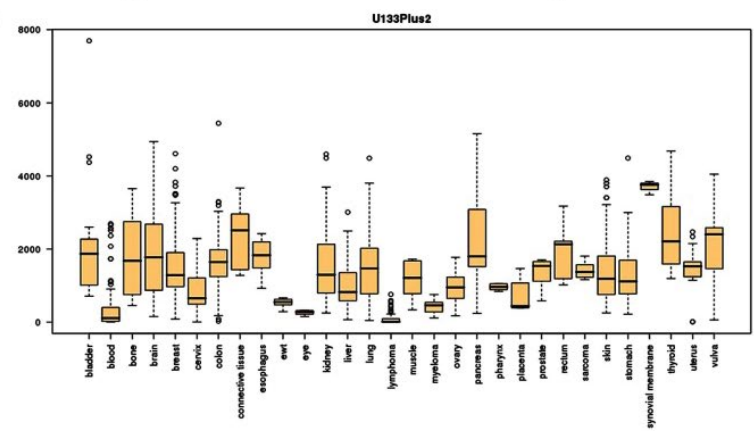

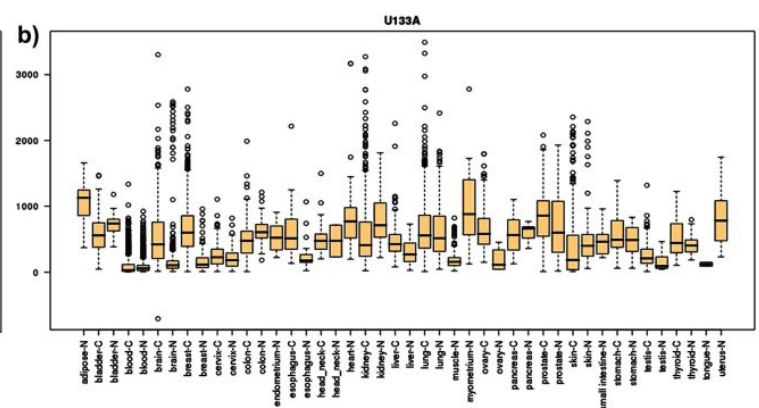

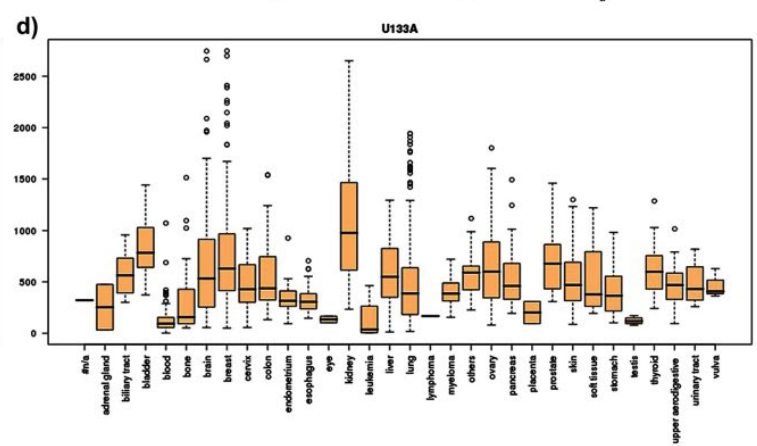

Figure 1: Pattern of CD151 expression across diverse normal tissues, tumour tissues and cell lines. U133plus2 data set (a) and U133A data set (b) of expression pattern of CD151 across diverse normal and tumour tissues. Expression pattern of CD151 in diverse cell lines (c and d). 
a)

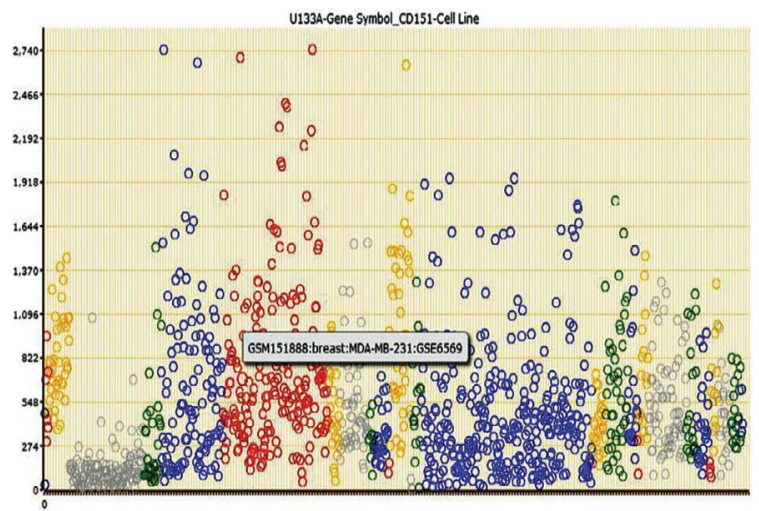

b)
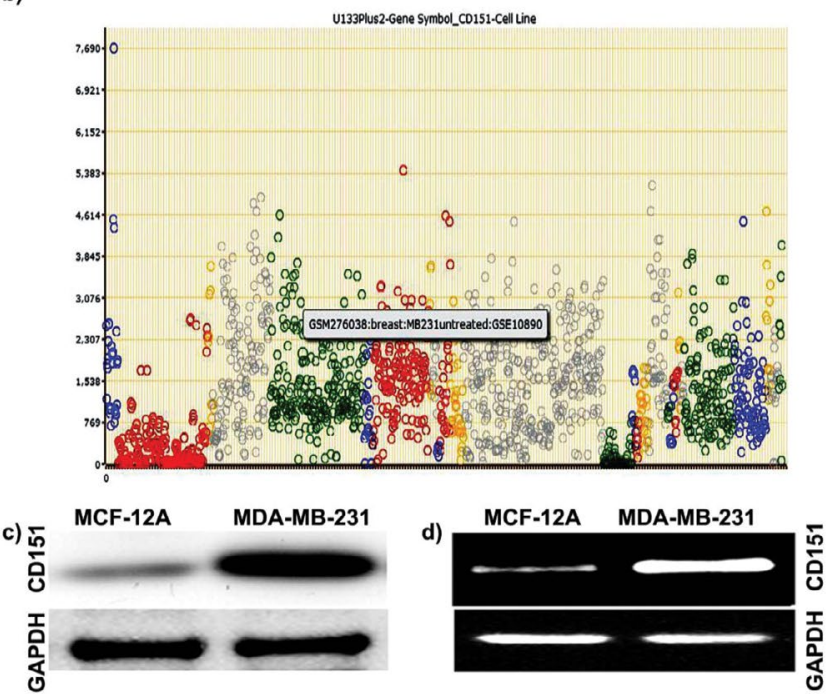

Figure 2: Expression of CD151 in human triple negative breast cancer cell line MDA-MB 231. Expression pattern of CD151 in MDA-MB-231 triple negative breast cancer cell line. a) U133A data and (b) U133plus2 data set of flash chart. Expression of CD151 in MDA-MB-231 breast cancer cells and MCF-12A normal breast epithelial cells as determined by Western blot (c) and RT-PCR analysis (d).

and $45.4 \%$ with shRNA-A; 41.7 and $37.3 \%$ with shRNA-B at 24 and $48 \mathrm{~h}$, respectively compared to $\mathrm{pSV}$ control indicating time dependent reduction of viability specific to CD151 gene silencing (Figure $4 \mathrm{~b}$ ). These outcomes imply that pCD-B (shRNA-B) has potential in silencing $\mathrm{CD} 151$ gene expression and cytotoxicity compared to pCD-A. Hence, pCD-B used for further studies and represented as pCD.

\section{Knockdown of CD151 expression by RNAi inhibits proliferation}

BrdU incorporation assay performed to analyze the effect of CD151down regulation on proliferation. The results showed that the knockdown of CD151 using CD151 shRNA resulted in a significant reduction of proliferation by 36 and $65 \%$ at 24 and $48 \mathrm{~h}$, respectively (Figure 4c) compared to pSV transfected cells, which set as $100 \%$.

\section{Knockdown of CD151 expression by RNAi induces apoptosis}

To investigate whether RNAi mediated CD151 down regulation induce apoptosis, MDA-MB-231 cells were transiently transfected with the pSV and $\mathrm{pCD}$ for 48 and $72 \mathrm{~h}$ and apoptosis was analysed by Tunnel assay (Figures $4 \mathrm{~d}$ and $4 \mathrm{e}$ ). The results show that apoptotic rate of $\mathrm{pCD}$ a)

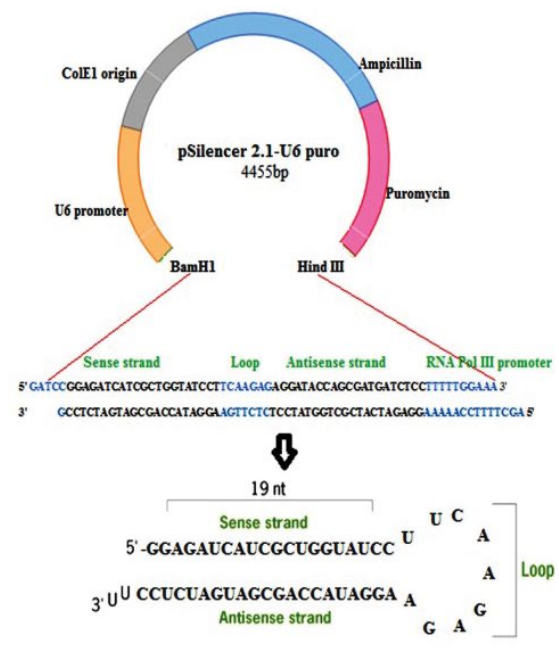

b)

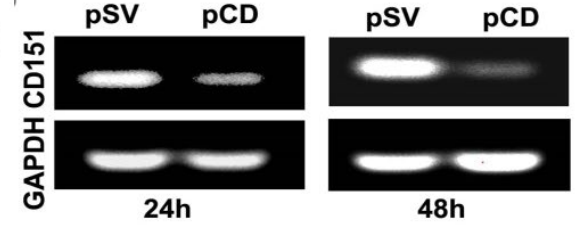

c)

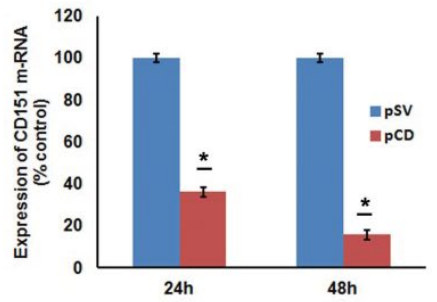

Figure 3: Targetting CD151 in MDA-MB-231 cells using shRNA construct a) Schematic representation of shRNA expressing plasmid construction from $p$ Silencer 2.1-u6 puro vector. b) Total RNA was isolated from pSV and pCD treated cells and expression of CD151 at mRNA level was determined by RT-PCR using specific primers. c) Quantitative analysis of CD151 mRNA expression by Image $\mathrm{J}$ software. The mean density of CD151 within the management cluster was outlined as $100 \%$. Data are presented as means $\pm \operatorname{SEM}\left(n=3,{ }^{*} p<0.001\right)$.

transfected cells was approximately 54 and $63 \%$, respectively at 48 and $72 \mathrm{~h}$ compared to DAPI stained cells (Figure 4f). However, apoptotic rate of pSV transfected cells was negligible. The results indicate that down regulation of CD151 expression by RNAi triggers apoptosis in MDA-MB- 231 cells.

Knockdown of CD151 expression by RNAi inhibits cell migration and invasive potential of MDA-MB-231 cells

The effect of CD151 gene silencing on migration of MDA-MB231cells was determined by wound scratch assay. The wound healing ability was observed after transfection with pSV and pCD at 0,24 and $48 \mathrm{~h}$. In pSV transfected cells, the area of wound was significantly decreased compared to pCD treated cells (Figure 5a). The wound area at $0 \mathrm{~h}$ was set as $100 \%$ in both pSV and pCD treated cells. The wound area at 24 and $48 \mathrm{~h}$ was 60 and $2 \%$, respectively in pSV treated cells, whereas 80 and $60 \%$, respectively in pCD treated cells compared to wound area at $0 \mathrm{~h}$. These results indicate that percent of wound repair in pCD treated cells decreased by $20 \%$ at $24 \mathrm{~h}$ and $58 \%$ at $48 \mathrm{~h}$ 
a)

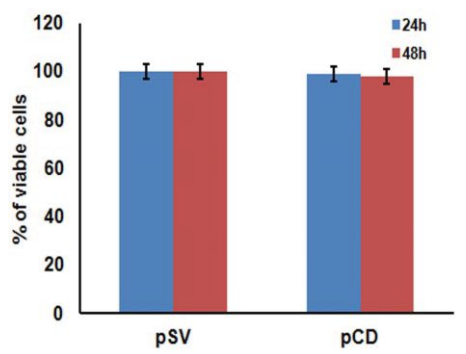

c)
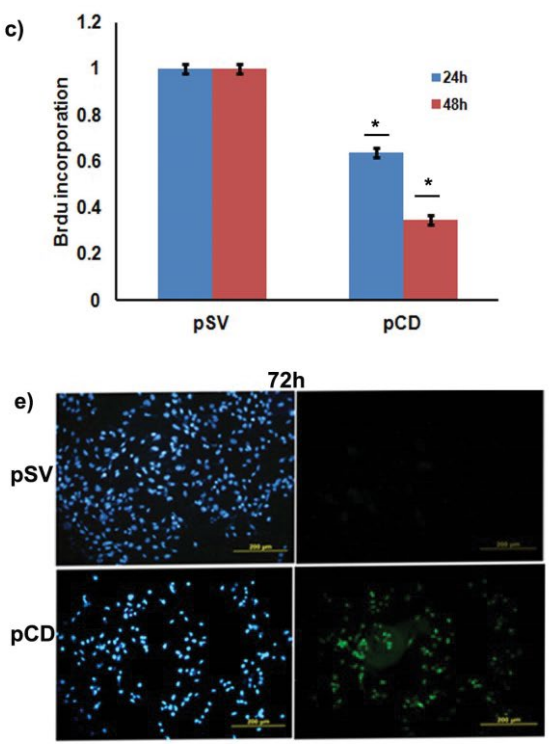

b)

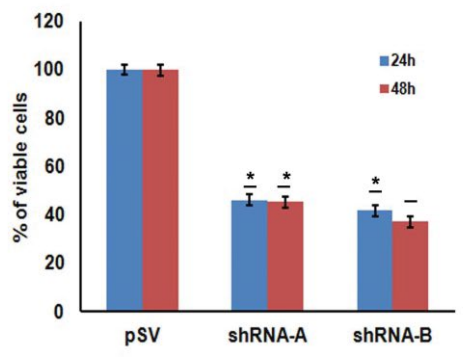

d)

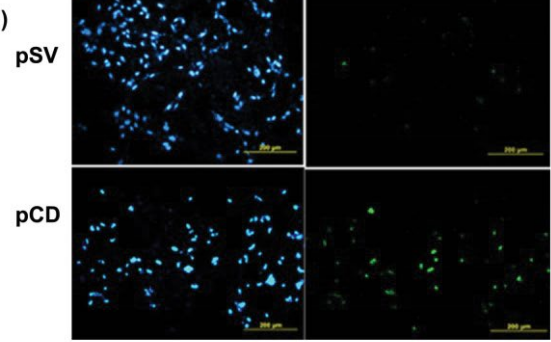

f)

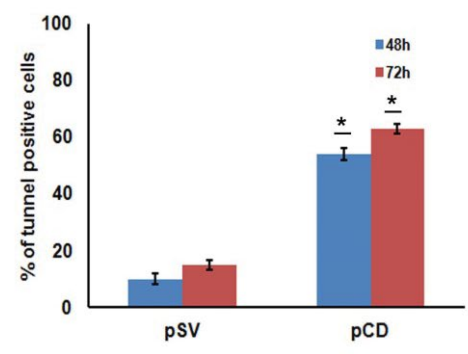

Figure 4: Effect of CD151 gene silencing on proliferation and apoptosis of MDA-MB-231 cells. Effect of pCD on viability of MCF-12A (a) and MDA-MB-231 (b) cells at 24 and $48 \mathrm{~h}$. Results were expressed in percent control. c) Effect of pCD on BrdU incorporation during proliferation of MDA-MB-231 cells. The results were expressed in percent control. Effect of pCD on induction of apoptosis in MDA-MB-231 cells at $48 \mathrm{~h}$ (d) $72 \mathrm{~h}$ (e). Tunnel positive cells were counted using Image $\mathrm{J}$ (NIH, USA) and expressed as percent of DAPI stained cells (f). The cumulative data of each assay was done from 3 independent experiments and shown as means $\pm S E M(n=3$, $\left.{ }^{*} p<0.001\right)$.

compared to $\mathrm{pSV}$ treated cells (Figure 5b). The most precarious nature of malignancy is metastatic potential. The down regulation of CD151 using pCD reduced the invasive potential of MDA-MB-231 cells through the Matrigel (Figure 5c). Quantification of results of matrigel invasion revealed a significant reduction of invasive potential of MDAMB-231 cells when subjected to treatment with pCD (58\%) compared to $\mathrm{pSV}$ control, which set as $100 \%$ (Figure 5d).

\section{Knockdown of CD151 expression by RNAi reduces ECM- mediated cell adhesion}

Adhesion of cancer cells to ECM components is required to perform key functions such as proliferation, cell cycle, migration, and tumour invasion $[34,35]$. Treatment with pCD for $48 \mathrm{~h}$ reduced adhesion of MDA-MB-231 cells in the order of collagen I, vitronectin, fibronection and laminin (Figure 5e). The percentage of reduction of cell adhesion to collagen I was $60 \%$, fibronectin was $48 \%$, vitronectin was $45 \%$ and laminin was $12 \%$ (Figure $5 f$ ). These results indicate significant reduction of MDA-MB-231 cell adhesion to collagen I followed by fibronectin by down regulation of $\mathrm{CD} 151$ with $\mathrm{pCD}$.

\section{Discussion}

CD151, a member of tetraspanin superfamily forms tetraspaninenriched microdomains (TEM) with various signalling molecules
[36,37], membrane receptors and other tetraspanins such as CD9, CD81 and CD63. CD151 associate with these proteins and serve as molecular facilitator [38]. Previous studies have shown that many cancer cell lines and cancer tissues had high expression of CD151 and related to poor prognosis [11]. Recent scientific research has verified correlation between CD151 expression and cancer development [39]. Evidence also supported contribution of CD151 in cancer metastasis [40].

Proteomics helps cancer research with aid of high-throughput screening of biomarkers and therapeutic goals. The biological properties of a protein molecule depend on its physical interaction with other molecules. In the present study, interaction partners with CD151 as a central molecule were retrieved from STRING database [41]. The analysis of data showed that CD151 exhibited interactions with high confidence score of 0.900 and functions in different cellular, biological and molecular processes. This study suggests that CD151 cooperates with other proteins as a part of functional module and deliver various biological functions [42]. Previously, Ranjan Prasad Devbhandari et al. used large-scale proteomics screening techniques to develop a map of extensive protein-protein network centered on CD151 [43]. Laetitia Zona et al. identified a subset of TEM protein association network of 169 proteins with HRas and CD81 using STRING analysis [44].

According to annotation from GO database, CD151 function 

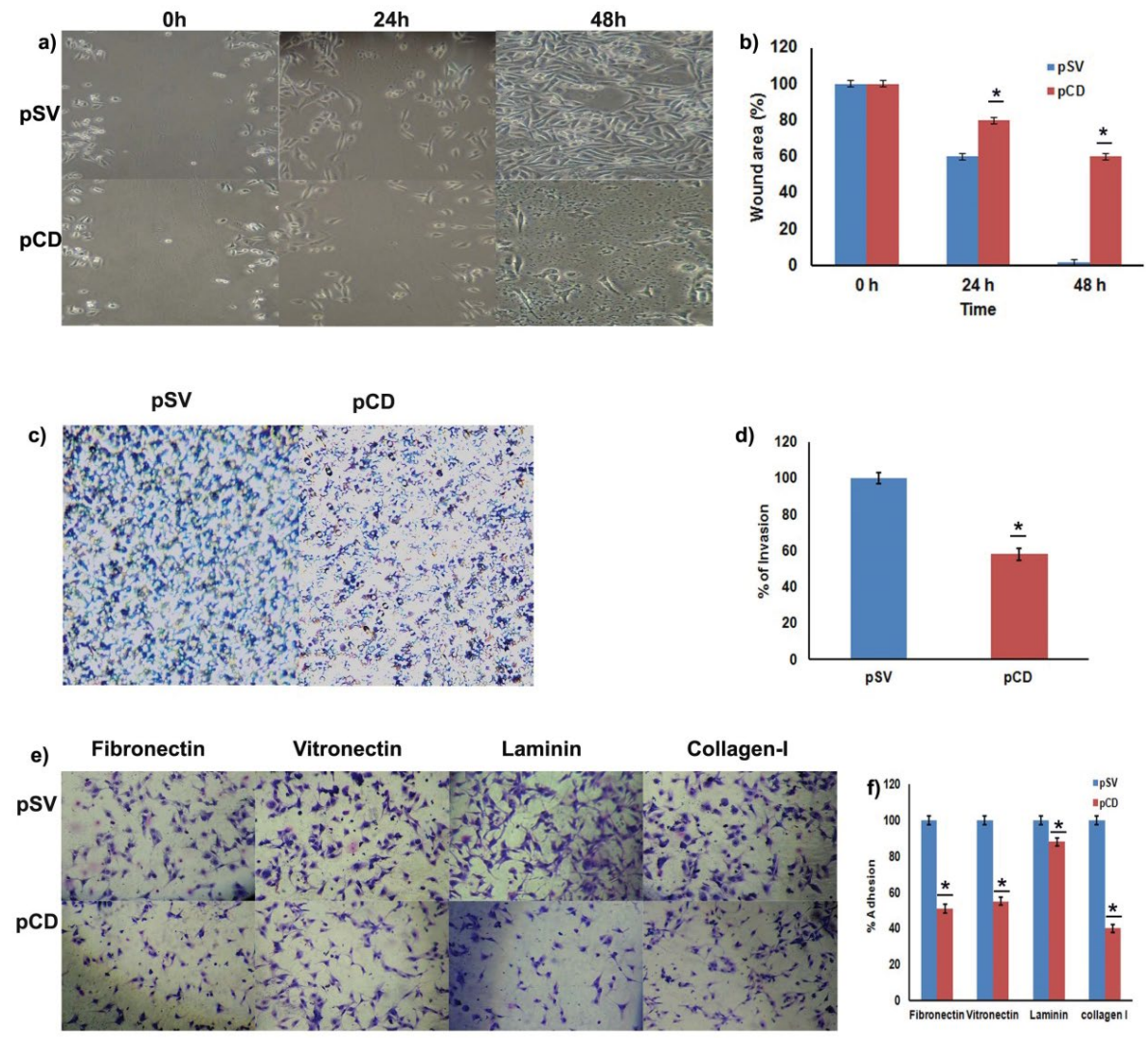

Figure 5: Effect of CD151 gene knockdown on metastasis of MDA-MB-231 cells. a) Effect of pCD on migration potential of MDA-MB-231 cells in Wound scratch assay. Cells were transfected with pSV and pCD for $48 \mathrm{~h}$, wound was made and wound healing potential was observed at 0,24 and $48 \mathrm{~h}$. b) Quantification of wound healing ability of MDA-MB-231 cells. Results were expressed as percent control. c) Effect of pCD on invasion potential of MDA-MB-231 cells through matrigel was evaluated using Boyden chamber assay. d) Quantification of invaded cells was expressed as percent control. e) Effect of pCD on adhesion of different ECM components was evaluated at $48 \mathrm{~h}$. Non-adherent cells were washed off and adherent cells were stained with Hema-3 staining. f) Adhesion of MDA-MB-231 cells transfected with CD151 shRNA to collagen-I was reduced compared to other ECM components, Percent of adhesion was calculated by setting adhesion of pSV treated cells as $100 \%$. The results of each experiment was obtained from three independent experiments and values shown as means \pm SEM $\left(n=3,{ }^{*} p<0.001\right)$.

in receptor binding, adhesion molecular binding and involved in extracellular matrix organization, hemidesmosome assembly and cellular component organization, cell junction assembly related to cancer progress [45]. Further, annotation of CD151 to tissues or to disease entities predicted that CD151 associate with breast glandular cells and breast cancer.

Further, CD151 expression pattern across diverse normal and tumour tissues, tissue sub-types and cancer cell lines was predicted using GENT database. The results demonstrated high expression of CD151 in breast tumour tissues compared to normal tissues. MDA-MB 231 cell lines was selected for CD151 gene silencing study based on information obtained from cell line database. This study predicted that MDA-MB-231 is a good cell line to demonstrate CD151 as a marker. For CD151 functional studies, we used two distinct but prototypical, myoepithelial-basal derived mammary cell lines, such as immortalized normal MCF-12A and malignant MDA-MB-231. The present study demonstrated the over expression of CD151 in triple negative breast cancer cell line, MDA-MB-231 using RT-PCR and Western blot analysis. However, non-cancerous breast epithelial cell line, MCF-12A expressed undetectable levels of this protein. These results are consistent with previous reports [46]. The potential relevance of CD151 with relative selectivity in cancers rather than normal tissues, it may consider as high-priority therapeutic target.
RNA interference is a biological mechanism by which doublestranded RNA (dsRNA) knockdown genes by targeting complementary mRNA. It is breakthrough in understanding regulation of gene expression in cells. RNA interference mediated gene silencing is tested in clinical trials for a number of diseases [47,48]. It also represents as an approach for drug discovery and development. Treatment of cancers using small interfering RNA (siRNA) has been a promising approach and actively explored as an alternative to chemotherapy $[49,50]$. The shRNA mediated RNAi has become a powerful tool for its specificity and efficiency to knock-down targets that cannot be readily downregulated by conventional chemotherapy.

pSilencer 2.1-U6 puro vector is most efficient transduction tool for the long-term study of gene specific knockdown (Ambion, Austin, TX, USA). In this study, linearized pSilencer 2.1-U6 puro was used for construction of vector encoding a small hairpin RNA (shRNA) directed against human CD151. The advantage of using shRNA over chemically synthesised siRNAs includes stable gene expression and long-term gene silencing effects with minimal cytotoxicity [51,52]. This vector has human U6 RNA pol III promoter, which is more effective for siRNA and provide high levels of constitutive expression across variety of cell types [53].

CD151 shRNA vector was efficiently transfected in to MDAMB-231 cells using Lipofectamine 3000 (Life Technologies, USA), 
which significantly silenced CD151 expression at mRNA level. MTT assay was originally used to measure the cytotoxic effect of drugs. The amount of formazan produced is proportional to metabolically active cells, which in turn indicates viability of the cells. CD151 gene knockdown via shRNA resulted significant decrease in viability of MDA-MB-231 cells compared to MCF-12A cells. These results were in concordance with the studies investigated the cytotoxic effect of CD151 towards human gastric carcinoma [9]. CD151 silencing using shRNA is neither affected proliferation nor survival of MCF-10A cells [10]. However, CD151 gene silencing via lentivirus-mediated CD151 specific shRNA arrested cell cycle in Go/G1 phase in MCF-7 and MDAMB-468 cells [54].

Adhesion of MDA-MB-231 cells to various ECM components plays a major role in tumour invasion cascade. Several studies have reported that CD151 form tight complexes with laminin binding integrins that promote tumour cell migration, invasion and proliferation [55]. CD151 in association with MMP-7 initiate cancer invasion and metastasis [56,57]. In the present study, CD151gene silencing caused significant reduction of MDA-MB-231 cell adhesion to collagen-I and moderate reduction to other ECM components. CD151 knockdown using shRNA significantly inhibited invasion of MDA-MB-231 cells through matrigel. Knockdown of CD151using shRNA has caused considerable inhibition of adhesion compared to other cancers [58]. Recent study have shown that knockdown of CD151 has a profound inhibitory effect on metastasis of MDA-MB-231 breast cancer cells [59].

CD151gene silencing significantly inhibited wound healing in wound scratch assay. In contrast, over expression of CD151 significantly increases intercellular adhesiveness and delays wound closure in a scratch assays [60]. Pengcheng et al. demonstrated that CD151-siRNA significantly decreased the cellular proliferation, migration, invasion and colony formation and enhanced apoptosis in lung cancer cell line, A549 [61]. Other studies have revealed that knockdown of CD151 by short-hairpin RNA decreased the cell motility, tumourigenicity, cell migration and decreases experimental metastasis [62] thus emphasizing CD151 as a potential marker [7]. As apoptosis has become a new therapeutic target in cancer research, our results found that knockdown of CD151 expression significantly induced apoptosis in MDA-MB-231 cells as demonstrated by a dramatic increase of TUNEL-positive cells. However, further investigation of its activity is necessary to elaborate and exploit this promise.

The present study conclude that CD151 is positively associate with the metastasis of triple negative breast cancer cell line, MDA-MB-231 and consider as a novel marker for predicting the prognosis of breast cancer patients and may be potential therapeutic targets.

\section{Acknowledgement}

The present research work was supported by DST-SERB, New Delhi, India (File No: SR/SO/BB-091/2012 dated: 20.06.2013). We thank the authorities of GITAM University for offering us facilities necessary to conduct this project.

\section{References}

1. Maweja S (2011) Surgical treatment of breast cancer. Rev Med Liege 66: 326328.

2. Richardson MM, Jennings LK, Zhang XA (2011) Tetraspanins and tumor progression. Clin Exp Metastasis 28: 261-270.

3. Bari R, Guo Q, Xia B, Zhang YH, Giesert EE, et al. (2011) Tetraspanins regulate the protrusive activities of cell membrane. Biochem Biophys Res Commun 415: 619-626.

4. Ang J, Fang BL, Ashman LK, Frauman AG (2010) The migration and invasion of human prostate cancer cell lines involves CD151 expression. Oncol Rep 24: 1593-1597.
5. Haeuw JF, Goetsch L, Bailly C, Corvaia N (2011) Tetraspanin CD151 as a targe for antibody-based cancer immunotherapy. Biochem Soc Trans 39: 553-558.

6. Fei Y, Wang J, Liu W, Zuo H, Qin J, et al. (2012) CD151 promotes cancer cell metastasis via integrins $\alpha 3 \beta 1$ and $\alpha 6 \beta 1$ in vitro. Mol Med Rep 6: 1226-1230.

7. Sadej R, Romanska H, Baldwin G, Gkirtzimanaki K, Novitskaya V, et al. (2009) CD151 regulates tumorigenesis by modulating the communication between tumor cells and endothelium. Mol Cancer Res 7: 787-798.

8. Johnson JL, Winterwood N, DeMali KA, Stipp CS (2009) Tetraspanin CD151 regulates RhoA activation and the dynamic stability of carcinoma cell-cell contacts. J Cell Sci 122: 2263-2273.

9. Franco M, Muratori C, Corso S, Tenaglia E, Bertotti A, et al. (2010) The tetraspanin CD151 is required for Met-dependent signaling and tumor cell growth. J Biol Chem 285: 38756-38764.

10. Sadej R, Romanska H, Kavanagh D, Baldwin G, Takahashi T, et al. (2010) Tetraspanin CD151 regulates transforming growth factor beta signaling: implication in tumor metastasis. Cancer Res 70: 6059-6070.

11. Yang XH, Richardson AL, Torres-Arzayus MI, Zhou P, Sharma C, et al. (2008) CD151 accelerates breast cancer by regulating alpha 6 integrin function, signaling, and molecular organization. Cancer Res 68: 3204-3213.

12. Hong IK, Jin YJ, Byun HJ, Jeoung DI, Kim YM, et al. (2006) Homophilic interactions of Tetraspanin CD151 up-regulate motility and matrix metalloproteinase- 9 expression of human melanoma cells through adhesiondependent C-Jun activation signaling pathways. J Biol Chem 281: 24279-24292.

13. Kazarov AR, Yang X, Stipp CS, Sehgal B, Hemler ME (2002) An extracellular site on tetraspanin CD151 determines alpha 3 and alpha 6 integrin-dependent cellular morphology. J Cell Biol 158: 1299-1309.

14. Ke AW, Shi GM, Zhou J, Huang XY, Shi YH, et al. (2011) CD151 amplifies signaling by integrin $\hat{I} \pm 6 \hat{I}^{2} 1$ to $\mathrm{PI} 3 \mathrm{~K}$ and induces the epithelial-mesenchymal transition in HCC cells. Gastroenterology 140: 1629-1641.

15. Bailey RL, Herbert JM, Khan K, Heath VL, Bicknell R, et al. (2011) The emerging role of tetraspanin microdomains on endothelial cells. Biochem Soc Trans 39: 1667-1673.

16. Novitskaya V, Romanska H, Dawoud M, Jones JL, Berditchevski F (2010) Tetraspanin CD151 regulates growth of mammary epithelial cells in threedimensional extracellular matrix: implication for mammary ductal carcinoma in situ. Cancer Res 70: 4698-4708.

17. Semenza GL (2008) Does loss of CD151 expression promote the metastasis of hypoxic colon cancer cells? Clin Cancer Res 14: 7969-7970.

18. Zijlstra A, Lewis J, Degryse B, Stuhlmann H, Quigley JP (2008) The inhibition of tumor cell intravasation and subsequent metastasis via regulation of in vivo tumor cell motility by the tetraspanin CD151. Cancer Cell 13: 221-234.

19. Sauer G, Kurzeder C, Grundmann R, Kreienberg R, Zeillinger R, et al. (2003) Expression of tetraspanin adaptor proteins below defined threshold values is associated with in vitro invasiveness of mammary carcinoma cells. Oncol Rep 10: $405-410$.

20. Schmelz M, Cress AE, Scott KM, Bürger F, Cui H, et al. (2002) Different phenotypes in human prostate cancer: alpha6 or alpha3 integrin in cellextracellular adhesion sites. Neoplasia 4: 243-254.

21. Kwon MJ, Park S, Choi JY, Oh E, Kim YJ, et al. (2012) Clinical significance of CD151 overexpression in subtypes of invasive breast cancer. $\mathrm{Br} \mathrm{J}$ Cancer 106: 923-930.

22. Kumari S, Devi G, Badana A, Dasari VR, Malla RR (2015) CD151-A Striking Marker for Cancer Therapy. Biomark Cancer 7: 7-11.

23. Chometon G, Zhang ZG, Rubinstein E, Boucheix C, Mauch C, et al. (2006) Dissociation of the complex between CD151 and laminin-binding integrins permits migration of epithelial cells. Exp Cell Res 312: 983-995.

24. Beckman RA, Weiner LM, Davis HM (2007) Antibody constructs in cancer therapy: protein engineering strategies to improve exposure in solid tumours Cancer 109: 170-179.

25. Jen KY, Gewirtz AM (2000) Suppression of gene expression by targeted disruption of messenger RNA: available options and current strategies. Stem Cells 18: 307-319.

26. Sibley CR, Seow Y, Wood MJ (2010) Novel RNA-based strategies for therapeutic gene silencing. Mol Ther 18: 466-476. 
Citation: Gayatri Devi V, Badana A, Kumari S, Nagaseshu P, Malla RR (2016) Therapeutic Potentials of CD151 shRNA in Targeting Metastasis of Triple Negative Breast Cancer Cell Line MDA-MB-231. J Cancer Sci Ther 8: 104-112. doi:10.4172/1948-5956.1000400

27. Wang XJ, Li Y, Huang $\mathrm{H}$, Zhang XJ, Xie PW, et al. (2013) A simple and robust vector-based shRNA expression system used for RNA interference. PLoS One 8: e56110.

28. Shin G, Kang TW, Yang S, Baek SJ, Jeong YS, et al. (2011) GENT: gene expression database of normal and tumor tissues. Cancer Inform 10: 149-157.

29. Elbashir SM, Martinez J, Patkaniowska A, Lendeckel W, Tuschl T (2001) Functional anatomy of siRNAs for mediating efficient RNAi in Drosophila melanogaster embryo lysate. EMBO J 20: 6877-6888.

30. Song $\mathrm{H}$, Yang PC (2010) Construction of shRNA lentiviral vector. N Am J Med Sci 2: 598-601.

31. Anders CK, Carey LA (2009) Biology, metastatic patterns, and treatment of patients with triple-negative breast cancer. Clin Breast Cancer 9 Suppl 2: S73-81.

32. Chavez KJ, Garimella SV, Lipkowitz S (2010) Triple negative breast cancer cell lines: one tool in the search for better treatment of triple negative breast cancer. Breast Dis 32: $35-48$.

33. Kunigal S, Lakka SS, Gondi CS, Estes N, Rao JS, et al. (2007) RNAi-mediated downregulation of urokinase plasminogen activator receptor (upar) and matrix metalloprotease-9 (mmp-9) in human breast cancer cells results in decreased tumour invasion, angiogenesis and growth. Int J Cancer 121: 2307-2316.

34. Ruoslahti E (1999) Fibronectin and its integrin receptors in cancer. Adv Cancer Res 76: 1-20.

35. Crowe DL, Shuler CF (1999) Regulation of tumor cell invasion by extracellular matrix. Histol Histopathol 14: 665-671.

36. Yauch RL, Berditchevski F, Harler MB, Reichner J, Hemler ME (1998) Highly stoichiometric, stable, and specific association of integrin alpha3beta1 with CD151 provides a major link to phosphatidylinositol 4-kinase, and may regulate cell migration. Mol Biol Cell 9: 2751-2765.

37. Zhang XA, Bontrager AL, Hemler ME (2001) Transmembrane-4 superfamily proteins associate with activated protein kinase $C(P K C)$ and link PKC to specific beta(1) integrins. J Biol Chem 276: 25005-25013.

38. Zöller M (2009) Tetraspanins: push and pull in suppressing and promoting metastasis. Nat Rev Cancer 9: 40-55.

39. Copeland BT, Bowman MJ, Ashman LK (2013) Genetic ablation of the tetraspanin CD151 reduces spontaneous metastatic spread of prostate cancer in the TRAMP model. Mol Cancer Res 11: 95-105.

40. Zijlstra A, Lewis J, Degryse B, Stuhlmann H, Quigley JP (2008) The inhibition of tumor cell intravasation and subsequent metastasis via regulation of in vivo tumor cell motility by the tetraspanin CD151. Cancer Cell 13: 221-234.

41. Szklarczyk D, Franceschini A, Wyder S, Forslund K, Heller D, et al. (2015) STRING $\vee 10$ : protein-protein interaction networks, integrated over the tree of life. Nucleic Acids Res 43: D447-452.

42. Gavin AC, Aloy P, Grandi P, Krause R, Boesche M, et al. (2006) Proteome survey reveals modularity of the yeast cell machinery. Nature 440: 631-636.

43. Devbhandari RP, Shi GM, Ke AW, Wu FZ, Huang XY, et al. (2011) Profiling of the tetraspanin CD151 web and conspiracy of CD151/integrin $\beta 1$ complex in the progression of hepatocellular carcinoma. PLoS One 6: e24901.

44. Zona L, Lupberger J, Sidahmed-Adrar N, Thumann C, Harris HJ, et al. (2013) HRas signal transduction promotes hepatitis $\mathrm{C}$ virus cell entry by triggering assembly of the host tetraspanin receptor complex. Cell Host Microbe 13: 302-313.

45. Zhang Z, Zhang L, Hua Y, Jia X, Li J, et al. (2010) Comparative proteomic analysis of plasma membrane proteins between human osteosarcoma and normal osteoblastic cell lines. BMC Cancer 10: 206.

46. Roselli S, Kahl RG, Copeland BT, Naylor MJ, Weidenhofer J, et al. (2014) Deletion of Cd151 reduces mammary tumorigenesis in the MMTV/PyMT mouse model. BMC Cancer 14: 509 .

47. Petrocca F, Lieberman J (2011) Promise and challenge of RNA interferencebased therapy for cancer. J Clin Oncol 29: 747-754
48. Li Z, Tian T, Hu X, Zhang X, Li L, et al. (2014) Targeting Six1 by lentivirusmediated RNA interference inhibits colorectal cancer cell growth and invasion. Int J Clin Exp Pathol 7: 631-639.

49. McManus MT, Sharp PA (2002) Gene silencing in mammals by small interfering RNAs. Nat Rev Genet 3: 737-747.

50. Kim DH, Rossi JJ (2007) Strategies for silencing human disease using RNA interference. Nat Rev Genet 8: 173-184.

51. Brummelkamp TR, Bernards R, Agami R (2002) A system for stable expression of short interfering RNAs in mammalian cells. Science 296: 550-553.

52. Sui G, Soohoo C, Affar el B, Gay F, Shi Y, et al. (2002) A DNA vector-based RNAi technology to suppress gene expression in mammalian cells. Proc Nat Acad Sci U S A 99: 5515-5520.

53. Elbashir SM, Harborth J, Lendeckel W, Yalcin A, Weber K, et al. (2001) Duplexe of 21-nucleotide RNAs mediate RNA interference in cultured mammalian cells. Nature 411: 494-498.

54. Liu T, wang S, Wang L, Wang J, Li Y (2015) Targeting CD151 by lentivirusmediated RNA interference inhibits luminal and basal-like breast cancer cell growth and invasion. Mol Cell Biochem 407: 111-121.

55. Gialeli C, Theocharis AD, Karamanos NK (2011) Roles of matrix metalloproteinases in cancer progression and their pharmacological targeting FEBS J 278: 16-27.

56. Hasegawa M, Furuya M, Kasuya Y, Nishiyama M, Sugiura T, et al. (2007) CD151 dynamics in carcinoma stroma interaction: integrin expression, adhesion strength and proteolytic activity. Lab Invest 87: 882-892.

57. Shiomi T, Inoki I, Kataoka F, Ohtsuka T, Hashimoto G, et al. (2005) Pericellula activation of proMMP-7 (promatrilysin-1) through interaction with CD151. Lab Invest 85: 1489-1506.

58. Veeravalli KK, Chetty C, Ponnala S, Gondi CS, Lakka SS, et al. (2010) MMP 9 , UPAR and cathepsin B silencing downregulate integrins in human glioma xenograft cells in vitro and in vivo in nude mice. PLoS ONE 5: e11583.

59. Gustafson-Wagner E, Stipp CS (2013) The CD9/CD81 tetraspanin complex and tetraspanin CD151 regulate $\alpha 3 \beta 1$ integrin-dependent tumor cell behaviors by overlapping but distinct mechanisms. PLoS One 8: e61834.

60. Shigeta M, Sanzen N, Ozawa M, Gu J, Hasegawa H, et al. (2003) CD151 regulates epithelial cell-cell adhesion through PKC- and Cdc42-dependen actin cytoskeletal reorganization. J Cell Biol 163: 165-176.

61. Li P, Zeng H, Qin J, Zou Y, Peng D, et al. (2015) Effects of tetraspanin CD151 inhibition on A549 human lung adenocarcinoma cells. Mol Med Rep 11: 1258 1265.

62. Mosig RA, Lin L, Senturk E, Shah H, Huang F, et al. (2012) Application of RNASeq transcriptome analysis: CD151 is an Invasion/Migration target in all stages of epithelial ovarian cancer. J Ovarian Res 5: 4. 